\title{
ANÁLISE DA EXPRESSÃO DOS GENES SERPINA1 E TFF3 NA PREDIÇÃO DO ENVOLVIMENTO DE LINFONODOS EM NEOPLASIAS MAMÁRIAS
}

\author{
Raissa Monteiro da Silva ${ }^{1}$ \\ Eliane Aline Ribeiro ${ }^{2}$ \\ Luis Henrique Ferreira de Moraes ${ }^{3}$ \\ Abaetê Leite do Canto ${ }^{4}$ \\ Renata de Azevedo Canevari ${ }^{5}$
}

\begin{abstract}
Resumo: O status dos linfonodos axilares é o fator prognóstico mais informativo no tratamento das pacientes com câncer de mama. Assim, a identificação de marcadores moleculares no tumor primário que possa permitir uma classificação mais precisa das pacientes em relação à necessidade, é extremamente importante para uma conduta clínica mais adequada. O objetivo deste estudo foi determinar se os genes SERPINA1 e TFF3 são marcadores preditivos em câncer de mama pela análise de expressão gênica de RT-qPCR. Para isto, foi comparado o grupo de tumores primários com envolvimento de linfonodos e tumores primários sem linfonodos acometidos, além da análise dos linfonodos correspondentes. Nossos resultados demonstraram que ambos os genes analisados não possuem papel preditivo relacionado ao desenvolvimento destes carcinomas.
\end{abstract}

Palavras-chave: Expressão gênica; Linfonodo axilar; Câncer de mama.

\footnotetext{
1 Graduanda em Biomedicina - Universidade do Vale do Paraíba - UNIVAP, Brasil. E-mail: raissa_monteiro_silva@uahoo.com.br.

2 Graduanda em Biomedicina - Universidade do Vale do Paraíba - UNIVAP, Brasil. E-mail: elianeribeiro319@gmail.com.

3 Médico Mastologista - Hospital São Francisco de Assis, Departamento de Mastologia / Jacareí, Brasil. E-mail: drluismoraes@hotmail.com.

4 Médico Patologista - Centro de Medicina Diagnóstica / São José dos Campos, Brasil. E-mail: abaete@cipax.com.br.

5 Professora Doutora e Pesquisadora na Universidade do Vale do Paraíba - UNIVAP, Brasil. E-mail: rcanevari@univap.br.
} 